$\mathrm{P}_{\mathrm{O}_{2}}$ and $\mathrm{P}_{\mathrm{CO} 2}$ in the initiation of respiration of fetal sheep. J. Appl. Physiol., 30 382 (9171).

19. Patel, M. J., Syanto, P., Yates, B., and Long, D. M.: Survival and histopathologic changes in lungs of hamsters following synthetic liquid breathing. Fed Proc., 29: 1740 (1970).

20. Rufer, R., and Spitzer, H. L.: Liquid ventilation in the respiratory distress syndrome. Chest, 66: 295 (1974).

21. Saga, S. J., Modell, J. H., Calderwood, H. W., Lucas, A. J., Tham, M. K., and Swenson, E. W.: Pulmonary function after ventilation with fluorocarbon liquid P-12F (CAroxin-F). J. Appl. Physiol., 34: 60 (1973).

22. Sargent, J. W., and Seffl, R. J.: Properties of perfluorinated liquids. Fed. Proc., 29: $1699(1970)$.

23. Sass, A. J., Wood, E. H., Greenleaf, J. F., Rittman, E. L., and Smith, H. C.: Effects of breathing liquid fluorocarbons on regional differences in pleural pressures and other physiological parameters (U.S.A.F. School of Aerospace Medicine, December, 1972).

24. Shaffer, T. H., and Moskowitz, G. D.: Demand-controlled liquid ventilation of the lungs. J. Appl. Physiol., 36: 208 (1974).

25. Shaffer, T. H., and Moskowitz, G. D.: An electromechanical demand regulated liquid breathing system. IEEE Trans. Biomed. Eng. 5: 412 (1975).
26. Shaffer, T. H., Arcinue, E., Paez, P., DuBois, A. B., and DelivoriaPapadopoulos, M. Variation of pulmonary mechanics and acid base balance in premature lambs during the first six hours of life. Fed. Proc., 34: 275 (1975).

27. Tuazon, J. G., Modell, J. H., Hood, C. I., and Swenson, E. W.: Pulmonary function after ventilation with fluorocarbon liquid (CAroxin-A). Anesthesia, 38: 134 (1973).

28. Zweizig, H. Z., Kuhl, D. E., Kutz, R., and Polgar, G.: Distribution of pulmonary blood flow in fetal and newborn lambs. Resp. Physiol., 8: 160 (1970).

29. The authors are grateful to Dr. Robert E. Forster for his valuable consultation and suggestions, and to Mr. Jonathan DeLong, Ms. Lee Gittens, and Ms. Monica Clossin for their technical assistance.

30. Drs. T. Shaffer and M. Delivoria-Papadopoulos were recipients of National Institutes of Health, Young Investigator Pulmonary Research Grant and Career Development Award, respectively.

31. The research leading to this paper was supported by the Public Health Service Grants nos. HC-17154, HD-07135, and HL-15061.

32. Requests for reprints should be addressed to: T. Shaffer, Ph.D., Department of Physiology, Medicine, and Pediatrics, School of Medicine, University of Pennsylvania, Philadelphia, Pa. 19174 (USA).

33. Accepted for publication November 17, 1975.

\title{
Lactate and Pyruvate as Fetal Metabolic Substrates
}

\author{
VALERIE CHARLTON CHAR ${ }^{(25)}$ AND ROBERT K. CREASY \\ Cardiovascular Research Institute and the Department of Obstetrics and Gynecology, University of \\ California at San Francisco, San Francisco, California, USA
}

\section{Extract}

Whole blood lactate, pyruvate, and oxygen concentrations were measured simultaneously in the umbilical vein, fetal femoral artery, maternal artery, and uterine vein in 14 chronically catheterized pregnant ewes and their fetuses. Lactate was found to be taken up in significant amounts across the placental circulation by the fetuses, whereas pyruvate was not.

The lactate concentration of fetal blood was higher than that of maternal blood; however, fetal lactate levels correlated with maternal arterial levels $(P \leq \mathbf{0 . 0 1})$. The mean lactate concentrations in all samples were: common umbilical vein, $2.105 \mathrm{mM}$; fetal femoral artery, $1.986 \mathrm{mM}$; and maternal artery, $0.823 \mathrm{mM}$. Where uterine venous lactate concentrations were measured, the lactate content of the uterine vein exceeded that of the maternal artery by a mean of $0.088 \mathrm{mmol} /$ liter $(P<\mathbf{0 . 0 0 5})$. The mean fetal gain in lactate across the placental circulation was $0.118 \mathrm{mmol} /$ liter $(P<0.005)$. This is equivalent to a gain of $1.2 \mathrm{~g}$ carbon $/ \mathrm{kg} / 24 \mathrm{hr}$ by the growing lamb fetus. The mean fraction of fetal oxygen consumption that could be accounted for by oxidation of lactate was 0.32 .

The pyruvate concentration of fetal blood was higher than that of maternal blood; however, fetal pyruvate levels correlated with maternal arterial levels $(P<\mathbf{0 . 0 5})$. The mean pyruvate concentrations in all samples were: common umbilical vein, $0.084 \mathrm{mM}$, fetal femoral artery, $0.094 \mathrm{mM}$; and maternal artery, 0.053 $\mathrm{mM}$. Where uterine venous pyruvate concentrations were measured, they exceeded the maternal arterial concentrations by a mean of $0.005 \mathrm{mmol} /$ liter $(P=0.001)$. Pyruvate appeared to be lost by the fetus across the placental circulation by a mean of 0.010 $\mathrm{mmol} /$ liter. This loss of pyruvate correlated with the placental fetal to maternal pyruvate concentration gradient $(P<0.05)$.
Correlations between maternal arterial and fetal lactate concentrations imply that fetal lactate levels are influenced by maternal levels. The increase in lactate concentration of both fetal and maternal blood during circulation through the placenta indicates placental production of lactate. The pyruvate concentrations observed, however, are consistent with either fetal to maternal flow of pyruvate or placental production.

\section{Speculation}

Lactate, after glucose and amino acids, is the third most important fetal substrate identified in the fetal lamb. Its role as a fetal fuel now needs to be evaluated in other animal species.

The pregnant sheep, surgically prepared with indwelling fetal and maternal catheters, is a useful animal model for studying fetal metabolism in an undisturbed physiologic state. With the use of this animal preparation glucose $(7,12)$, fructose (17), amino acids $(8,10)$ ketones $(13)$, glycerol, free fatty acids $(11,19)$ and acetate (6) have been investigated as possible fetal fuels. Of these substances only glucose, amino acids, and acetate have been shown to cross the placenta in significant amounts for use in fetal metabolism. Analyses of the carbon content of the lamb fetus and its waste products indicate that at least $7.69 \mathrm{~g}$ carbon $/ \mathrm{kg} / 24 \mathrm{hr}$ must be supplied to the fetus during the last one-third of gestation (2). Glucose, amino acids and acetate can account for only $77 \%$ of this carbon and their metabolism can account for, at most, $80 \%$ of the fetal oxygen consumption $(2,6,10,12)$. Additional substrates must therefore be used by the fetus in large amounts.

Lactate and pyruvate are fundamental intermediates in carbohy- 
drate metabolism. By themselves they can serve as the sole energy source for early mammalian embryo development in vitro (9). Using a sheep preparation with indwelling catheters, we investigated the possibility that lactate and pyruvate were fetal substrates. We found that large quantities of lactate are taken up by

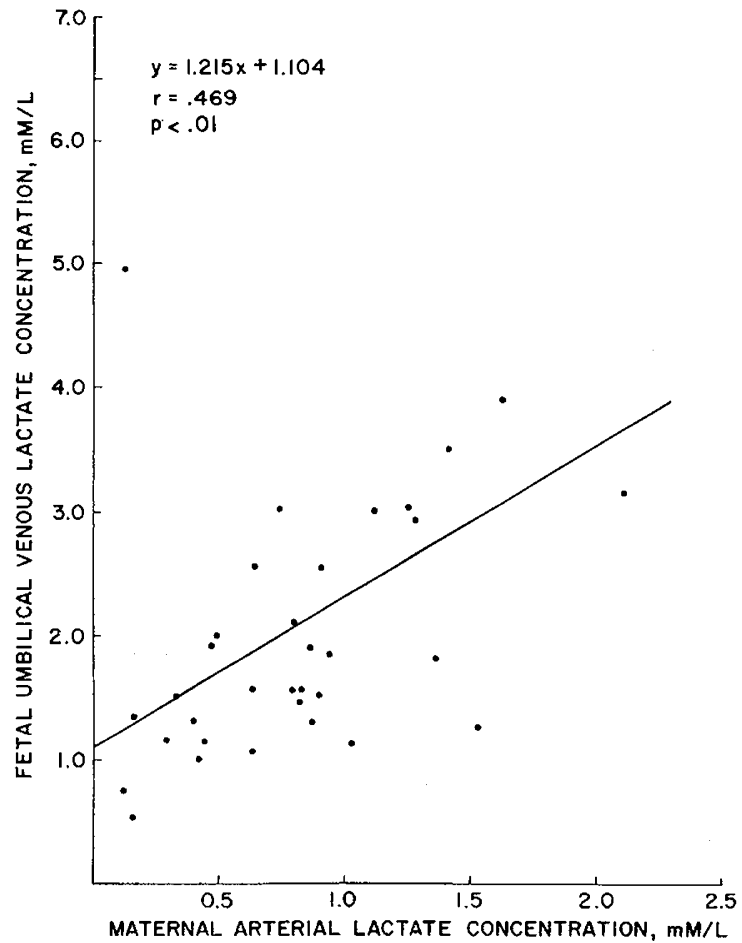

Fig. 1. Relationship between maternal arterial lactate concentration and fetal umbilical venous lactate concentration. (The plot of the regression of fetal arterial lactate concentration on maternal arterial lactate concentration, not shown, was similar with $y=1.147 \times+1.040 ; r=0.433, P=$ 0.01.) the fetus across the umbilical circulation, whereas pyruvate, in contrast, is not taken up. Data recently published by others (5) is in agreement with these findings.

\section{MATERIALS AND METHODS}

\section{ANIMAL PREPARATION}

We: wsed 14 pregnant sheep of known gestational ages that were fastedl for $24 \mathrm{hr}$ before sugical preparation. Surgery was performed under low spinal anesthesia with $1 \%$ tetracaine hydrochloride. Polyvinyl catheters (French no. 8) were first placed in the maternal femoral artery and vein. Then the uterus was exposed through an abdominal incision: and polyvinyl catheters $(0.030$ inch I.D. and 0.48 inch O.D.) placed in the fetal femoral artery and vein and in the common umbilical vein, as we have previously described (20). An open-ended polyvinyl catheter (French no. 8) was placed in the amniotic cavity. In 11 of the ewes, after closure of the uterine incision, a catheter (0.030 inch I.D. and 0.48 inch O.D.) was placed in a uterine vein and advanced into the main uterine vein, draining the pregnant horn. All catheters were brought out through a stab wound in the maternal flank where they were protected by a Teflon patch (14). Kanamycin, $200 \mathrm{mg}$, was instilled into the amniotic cavity for 5 days after surgery. The catheters were flushed with saline and filled with heparin, $1000 \mathrm{U} / \mathrm{ml}$, daily, After surgery, the ewes were allowed to feed on alfalfa pellets and water ad libitum.

\section{EXPERIMENTAL DESIGN}

Each day after surgery, the pregnant ewes were brought into the laboratory from their stalls in mobile cages for at least $2 \mathrm{hr}$. During this time they had access to food and water. All blood samplings for lactate and pyruvate were done in the midmorning on well oxygenated fetuses with normal femoral arterial $\mathrm{pH}$ and blood gases $\left(\mathrm{pH}>7.30, \mathrm{paO}_{2}>18, \mathrm{paCO}_{2}<55\right.$ ). Thirty-four studies for lactate content and 24 studies for pyruvate content were done on 14 fetuses of 110-133 days of gestation and 1-22 days (mean of 7 days) after surgery. Aliquots of blood, $2.5 \mathrm{ml}$, were withdrawn simultaneously from all catheterized vessels into hepa-

Table 1. Data from studies for lactate $/ \mathrm{O}_{2}$ ratios ${ }^{1}$

\begin{tabular}{|c|c|c|c|c|}
\hline Animal & Gestation, days & $\begin{array}{c}\text { CUV-FA lactate } \\
\text { concentration, } \mathrm{mM} / \text { liter }\end{array}$ & $\begin{array}{c}\text { CUN-FA: } \mathrm{O}_{2} \\
\text { concentration, } \mathrm{mM} / \text { liter }\end{array}$ & $\begin{array}{l}\text { Lactate } / \mathrm{O}_{2} \\
\quad \text { ratio }\end{array}$ \\
\hline \multirow[t]{2}{*}{1190} & 111 & 0.193 & 2.098 & 0.276 \\
\hline & 118 & 0.164 & 2.146 & 0.229 \\
\hline \multirow{3}{*}{2147} & 116 & 0.100 & 0.491 & 0.610 \\
\hline & 127 & 0.184 & 1.651 & 0.335 \\
\hline & 133 & 0.783 & 2.321 & 1.012 \\
\hline 2153 & 120 & 0.040 & 1.160 & 0.103 \\
\hline 2154 & 115 & 0.206 & 1.603 & 0.386 \\
\hline \multirow[t]{3}{*}{2167} & 116 & -0.145 & 1.562 & $0.000^{2}$ \\
\hline & 122 & 0.364 & 1.830 & 0.597 \\
\hline & 129 & 0.058 & 2.009 & 0.086 \\
\hline 2173 & 120 & 0.169 & 1.474 & 0.343 \\
\hline \multirow{2}{*}{2177} & 118 & 0.154 & 1.964 & 0.236 \\
\hline & 122 & 0.142 & 1.785 & 0.239 \\
\hline \multirow[t]{2}{*}{2178} & 114 & -0.095 & 1.786 & $0.000^{2}$ \\
\hline & 117 & 0.090 & 2.054 & 0.131 \\
\hline \multirow[t]{2}{*}{ Mean \pm SEM } & & 0.172 & 1.591 & $0.324^{3-}$ \\
\hline & & 0.044 & 0.094 & \\
\hline
\end{tabular}

${ }^{1}$ CUV: common umbilical vein; FA: fetal femoral artery.

${ }^{2}$ Lactate $/ \mathrm{O}_{2}$ ratio in these cases is taken as 0.000 , since $0 \%$ of the fetal oxygen consumption is accounted for by lactate metabolism.

${ }^{8}$ Calculated using the mean lactate and oxygen uptakes. 
rinized syringes. Measurements of whole blood lactate and pyruvate concentrations were begun immediately. During 22 studies in 13 fetal lambs, an additional 1 mil of blood was drawn from the fetal vessels and analyzed for oxygen content. Using these measurements, the lactate $/ \mathrm{O}_{2}$ ratio, the fraction of fetal oxygen consumption that would be consumed in completely oxidizing lactate to $\mathrm{CO}_{2}$ and water, was calculated. Since $3 \mathrm{~mol}$ oxygen are needed to oxidize each mole of lactate, the lactate to $\mathrm{O}_{2}$ ratio was defined as: $(3 \times \Delta$ lactate $) / \Delta \mathrm{O}_{2}$. Where $\Delta$ lactate and $\Delta \mathrm{O}_{2}$ represent the umbilical venous-arterial differences of lactate and oxygen, respectively, in millimoles per liter.

\section{ANALYTICAL METHODS}

Whole blood lactate and pyruvate concentrations were measured enzymatically using lactic dehydrogenase (15) and standard commercial reagents (21). Our mean percentage of error in duplicate fetal blood samples was $3.2 \%$ and on maternal samples was $6.8 \%$. Oxygen content was measured on the Lex- ${ }_{2}$-Con (22). The accuracy of this method has been documented (18) and was substantiated in our laboratory by periodic checks with Van Slyke $\mathrm{O}_{2}$ contents.

Statistical analysis of our data was performed using the paired $t$-test and the correlation coefficient, where appropriate.

\section{RESULTS}

\section{LACTATE}

The lactate concentration in fetal venous and arterial blood was always higher than in maternal venous and arterial blood. Both fetal umbilical venous and femoral arterial lactate levels correlated significantly with the maternal arterial levels (Fig. 1). The mean lactate concentrations for the 34 measurements were: common umbilical vein (CUV), 2.105 \pm 0.215 SEM mM; fetal femoral artery (FA), $1.986 \pm 0.220 \mathrm{mM}$; and maternal artery (MA), $0.823 \pm 0.083$ SEM $\mathrm{mM}$. The mean CUV-FA lactate

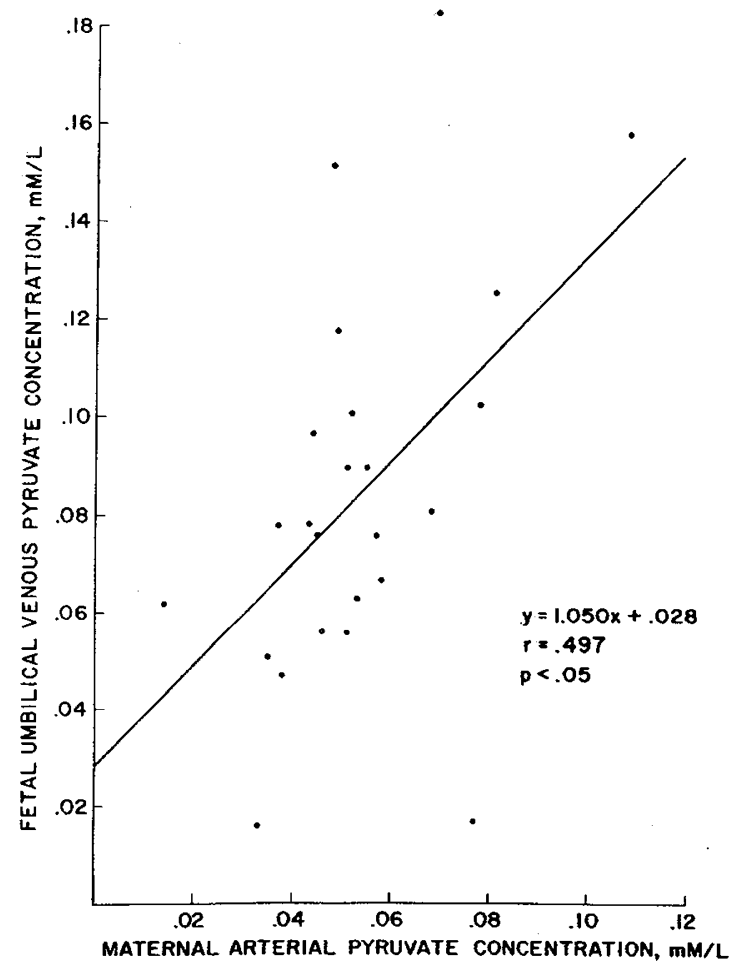

Fig. 2. Relationship between maternal arterial pyruvate concentration and fetal umbilical venous pyruvate concentration. (The plot of the regression of fetal arterial pyruvate concentration on maternal arterial pyruvate concentration, not shown, was similar with $y=1.659 \times+0.005$, $r=0.708, P<0.001$.) difference was $0.118 \pm 0.034 \mathrm{SEM} \mathrm{mmol} /$ liter $(1.07 \pm 0.308$ SEM mg/ $100 \mathrm{ml}$ ), a highly significant difference with $P<0.005$.

In the 28 studies in which uterine venous lactate concentrations were measured, the mean maternal arterial and uterine venous (UtV) lactate values were $0.847 \pm 0.095 \mathrm{SEM} \mathrm{mM}$ and $0.936 \pm 0.093 \mathrm{mM}$, respectively. The uterine venous concentration was significantly higher by a mean of $0.088 \pm 0.026$ SEM $\mathrm{mmol} /$ liter, with $P<0.005$.

The results from the 22 studies in which oxygen content was measured and lactate $/ \mathrm{O}_{2}$ ratios calculated are presented in Table 1. Of the 22 CUV-FA sample pairs analyzed for oxygen content, 3 had a slightly higher lactate concentration in the FA than in the CUV. In these instances the lactate $/ \mathrm{O}_{2}$ ratio is considered to be zero, since $0 \%$ of the fetal oxygen consumption is accounted for by lactate metabolism. The mean lactate $/ \mathrm{O}_{2}$ ratio, calculated using the mean lactate and oxygen uptakes in these studies, is 0.324 .

\section{PYRUVATE}

The pyruvate content of either fetal venous or arterial blood was higher than of either maternal venous or arterial blood. Fetal umbilical venous and femoral arterial pyruvate levels correlated with maternal arterial levels (Fig. 2). Twenty-four measurements of pyruvate concentration were done on the CUV, FA, and MA. The mean pyruvate concentration for each vessel was: CUV, 0.084 \pm 0.008 SEM mM; FA $0.094 \pm 0.009$ SEM mM; and MA, 0.053 $\pm 0.003 \mathrm{SEM} \mathrm{mM}$. In 15 out of the 24 CUV-FA sample pairs, the pyruvate concentration was higher in the fetal artery. The mean FA-CUV difference was $0.010 \pm 0.006 \mathrm{SEM} \mathrm{mmol} /$ liter, which is not statistically significant. However, a correlation was found between the pyruvate concentration gradient across the placenta (FA-MA) and fetal loss of pyruvate (FA-CUV difference) (Fig. 3).

In 18 studies, the uterine venous pyruvate concentration was measured. In these samples the mean pyruvate concentration in the UtV was $0.057 \pm 0.003 \mathrm{mM}$ and in the maternal artery was 0.052 $\pm 0.004 \mathrm{SEM} \mathrm{mM}$. The mean UtV-MA pyruvate difference was $0.005 \pm 0.001 \mathrm{SEM} \mathrm{mmol} /$ liter, a highly significant difference with $P<0.001$.

In both fetal vessels studied, the pyruvate levels showed

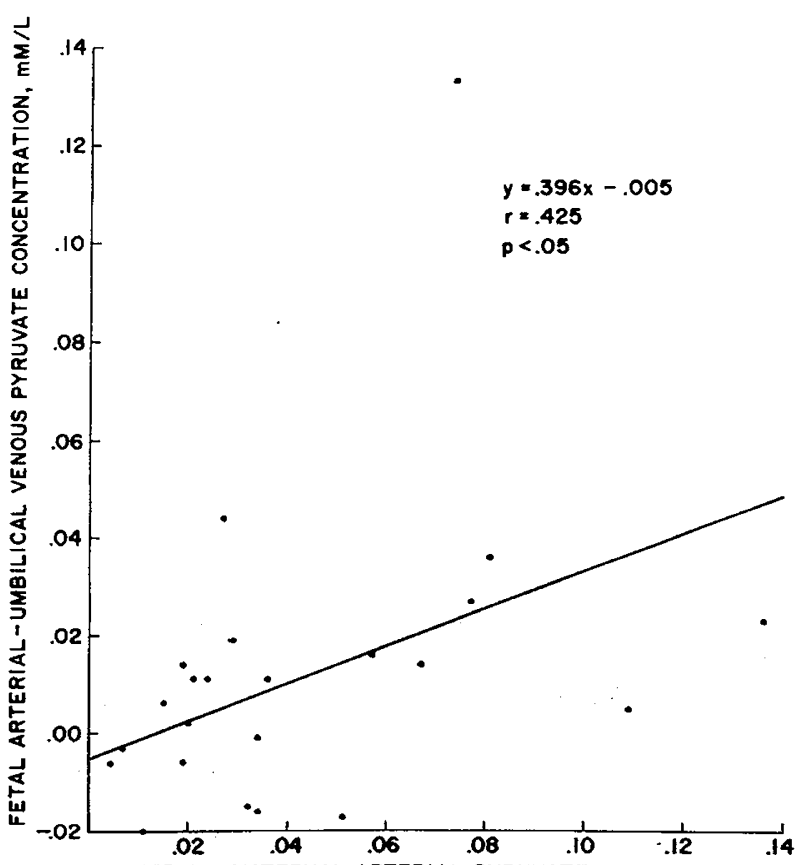

FETAL ARTERIAL-MATERNAL ARTERIAL PYRUVATE CONCENTRATION, mM/L

Fig. 3. Relationship between the pyruvate concentration gradient across the placenta (fetal femoral artery-maternal arterial) and fetal loss of pyruvate across the placenta (fetal femoral artery-common umbilical vein). 
significant correlation with the lactate levels $(P<0.01$ in the common umbilical vein and $P<0.001$ in the fetal femoral artery).

\section{DISCUSSION}

The $0.118 \mathrm{mmol} /$ liter lactate being taken up by the fetal lamb across the placental circulation represents a large contribution to fetal metabolism. Assuming a mean umbilical blood flow of 200 $\mathrm{cc} / \mathrm{kg} / \mathrm{min}$ in the last third of gestation in the lamb (14), 33.98 $\mathrm{mmol} / \mathrm{kg} / 24 \mathrm{hr}(3.08 \mathrm{~g} / \mathrm{kg} / 24 \mathrm{hr})$ lactate is being utilized. Lactate is therefore one of the major fetal substrates, only glucose and amino acids being quantitatively more important.

Of the $7.69 \mathrm{~g}$ carbon $/ \mathrm{kg} / 24 \mathrm{hr}$ crossing the placenta to the lamb fetus during the last one-third of gestation, the amount of carbon per $\mathrm{kg} / 24 \mathrm{hr}$ provided by fetal glucose uptake is between 1.8 and 2.6 grams $(7,12)$ and by acetate uptake is $0.56 \mathrm{~g}(6)$. Calculations based on nitrogen balance studies in the fetal lamb, using an average $\mathrm{C}$ to $\mathrm{N}$ ratio in amino acids of $3.3(2)$, indicate that $3.16 \mathrm{~g}$ carbon $/ \mathrm{kg} / 24 \mathrm{hr}$ reach the fetus as amino acids. Lactate contains $0.036 \mathrm{~g}$ carbon $/ \mathrm{mmol}$ and in the quantity being taken up would supply the lamb fetus with an additional $1.22 \mathrm{~g}$ carbon $/ \mathrm{kg} / 24 \mathrm{hr}$. With the identification of lactate as a fetal substrate we can now account for a total of $7.14 \mathrm{~g}$ carbon $/ \mathrm{kg} / 24 \mathrm{hr}$ or $92 \%$ of fetal carbon supplies.

Assuming that all the glucose and acetate taken up by the fetus is oxidized, $80 \%$ of the fetal lamb's daily oxygen consumption can be accounted for by oxidation of these two substances $(6,12)$ and catabolism of amino acids (10). The lactate $/ \mathrm{O}_{2}$ ratio indicates that approximately $32 \%$ of the oxygen consumption could also be used in complete oxidation of lactate. Assuming oxidation of the identified fetal substrates and using our figure of $32 \%$, we are now in the position of accounting for more than $100 \%$ of the fetal lamb's daily oxygen consumption. This is not surprising since all of the fetal substrates cannot be oxidized in toto. A proportion of them must be used in synthetic reactions in the growing fetus.

Lactate must be converted into pyruvate in order to be metabolized, and correlations between circulating levels of lactate and pyruvate are not unexpected. Lactate, once converted to pyruvate, can be used by the fetal lamb in gluconeogenesis (1) or oxidized in the Krebs cycle.

The concept that lactate can be taken up and utilized by the fetus is a new one. Past experiments were aimed at evaluating fetal or maternal lactate flow and indicated that the sheep placenta was impermeable to lactate $(3,4)$. Movement of lactate from the fetus to the ewe was seen only at extremely high, abnormal fetal lactate levels (4). Recently Burd et al. (5) have reported their studies on fetal lactate metabolism in a chronic sheep preparation. They reached conclusions similar to ours, finding a significant umbilical venous-umbilical arterial lactate difference of $0.16 \mathrm{mmol} /$ liter that could account for approximately $25 \%$ (range $0-79 \%$ ) of their fetuses oxidative metabolism. With documentation that lactate is taken up by the fetus across the placental circulation, the previously seen low diffusibility of lactate back toward the ewe is not surprising.

The source of the lactate that is being transferred to the fetus is unclear. Correlations between maternal arterial and fetal lactate concentrations imply that fetal levels are influenced by maternal levels. If maternal blood serves as a source of fetal lactate, active transport across the placenta against a concentration gradient is involved. However, maternal uterine blood does not lose, but gains lactate, an observation substantiated by others (5). Most likely, the sheep placenta, which is known to produce lactate from other substrates (16), is depositing it into both the fetal and maternal circulations.

Pyruvate, in contrast to lactate, is not taken up by the fetus and makes no measurable contribution as a fetal substrate. The significantly higher pyruvate levels in the uterine vein than in the maternal artery and the trend toward higher values in the fetal artery than in the umbilical vein are consistent with a net movement of pyruvate from fetus to mother. A similar observation was made in experiments on the acutely hypoxic exteriorized fetus (4). Alternatively, the placenta could be producing pyruvate and supplying it to the maternal circulation.

\section{SUMMARY}

Lactate and pyruvate concentration differences across the fetal umbilical circulation and the maternal uterine circulation were measured in a chronic sheep preparation. Significant gains in lactate in both the fetal and maternal circulations were observed. The lactate taken up by the fetus would account for $32 \%$ of fetal oxygen consumption if oxidized. There was no significant change in pyruvate concentration across the fetal umbilical circulation; however, pyruvate was gained by maternal uterine blood.

\section{REFERENCES AND NOTES}

1. Ballard, F. J., and Oliver, I. T.: Carbohydrate metabolism in liver from foetal and neonatal sheep. Biochem. J., 95: 191 (1965).

2. Battaglia, F. C., and Meschia, G.: Foetal metabolism and substrate utilization. Foetal and Neonatal Physiology, p. 382 (Cambridge University Press, Cambridge, England, 1973).

3. Britton, H. G., Huggett, A. St. G., and Nixon, D. A.: Carbohydrate metabolism in the sheep placenta. Biochem. Biophys. Acta, 136: 426 (1967).

4. Britton, H. G., Nixon, D. A., and Wright, G. H.: The effects of acute hypoxia on the sheep foetus and some observations on recovery from hypoxia. Biol. Neonate, 11: 277 (1967).

5. Burd, L. I., Jones, M. D. Jr., Simmons, M. A., Makowski, E. L., Meschia, G., and Battaglia,F. C.: Placental production and foetal utilisation of lactate and pyruvate. Nature, 254: 710 (1975).

6. Char, V. C, and Creasy, R. K.: Acetate as a metabolic substrate in the fetal lamb. Amer. J. Physiol. 230: 357 (1976)

7. Crenshaw, C.: Fetal glucose metabolism. Clin. Obstet. Gynecol., 13:579 (1970).

8. Curet, L.: Physiological aspects of amino acid transport across the placenta. Clin. Obstet. Gynec., 13: 586 (1970)

9. Daniel, J. C.: The pattern of utilization of respiratory metabolic intermediates by preimplantation rabbit embryos in vitro. Exp. Cell. Res., 47: 619, (1967).

10. Gresham, E. L., James, E. J., Raye, J. R., Battaglia, F. C., Makowski, E. L., and Meschia, G.: Production and excretion of urea by the fetal lamb. Pediatrics, 50: 372 (1972).

11. James, E. J., Meschia, G., and Battaglia, F. C.: A-V differences of free fatty acids and glycerol in the ovine umbilical circulation. Proc. Soc. Exp. Biol. Med., 138: 823 (1971).

12. James, E. J., Raye, J. R., Gresham, E. L., Makowski, E. L., Meschia, G., and Battaglia, F. C.: Fetal oxygen consumption, carbon dioxide production, and glucose uptake in a chronic sheep preparation. Pediatrics, 50:361 (1972).

13. Morriss, F. H., Boyd, R. D., Makowski, E. L., Meschia, G.- and Battaglia, F. C.: Umbilical V-A differences of acetoacetate and B-hydroxybutrate in fed and starved ewes. Proc. Soc. Exp. Biol. Med., 145: 879 (1974).

14. Rudolph, A. M., and Heymann, M. A.: The circulation of the fetus in utero. Circ. Res., 21: 163 (1967).

15. Sigma Technical Bulletin no. 726/826-UV (Sigma Chemical Co., St. Louis, Mo., 1968).

16. Simmons, M., Burd, L., Lemons, J., Jones, M. D. Jr., Schreiner, R., Meschia, G., and Battaglia, F.: Placental utilization and conversion of glucose in vivo [Abstract]. Pediat. Res., 9: 279 (1975).

17. Tsoulos, N. G., Colwill, J. R., Battaglia, F. C., Makowski, E. L., and Meschia G.: Comparison of glucose, fructose, and $\mathrm{O}_{2}$ uptakes by fetuses of fed and starved ewes. Amer. J. Physiol., 221: 234 (1972).

18. Valeri, C. R., Zaroulis, C. G., Marchionni, L., and Patti, K. J.: A simple method for measuring oxygen content in blood. J. Lab. Clin. Med., 79: 1035 (1972).

19. Van Duyne, C. M., Parker, H. R., Havel, R. J., and Holm, L. W.: Free fatty acid metabolism in fetal and newborn sheep. Amer. J. Physiol., 199: 987 (1960).

20. Young, W. P., Creasy, R. K., and Rudolph, A. M.: Catheterization of the common umbilical vein for chronic fetal lamb studies. J. Appl. Physiol., 37: 620 (1974).

21. Sigma Chemical Co., St. Louis, Mo.

22. Lexington Instrument Corp., Waltham, Mass.

23. Dr. V. C. Char was supported by National Institutes of Health Graduate Training Grant HL05251.

24. This research was supported by United States Public Health Service Grant HD06619.

25. Requests for reprints should be addressed to: V. C. Char, M.D., Cardiovascular Research Institute, University of California, 1410 HSE, San Francisco, Calif. 94143 (USA).

26. Accepted for publication November 17, 1975. 